\title{
Numerical Evaluation of Static Behavior of Stud Shear Connectors
}

\author{
スタッドの静的挙動の数值解析的検討
}

\author{
Md. Khasro MIAH*, Isao SAIKI** and Akinori NAKAJIMA*** \\ モハマド・コシュール・ミヤー, 斉木 功, 中島章典
}

\begin{abstract}
${ }^{*}$ Graduate student, Production and Information Science, Graduate School of Eng., Utsunomiya University (7-1-2 Yoto, Utsunomiya 321-8585, Japan) E-mail: dt020009@cc.utsunomiya-u.ac.jp

${ }^{* *}$ Dr. Eng., Research Associate, Dept. of Civil Eng., Utsunomiya University (7-1-2 Yoto, Utsunomiya 321-8585, Japan) E-mail: saiki@cc.utsunomiya-u.ac.jp

${ }^{* * *}$ Dr. Eng., Professor, Information and Control Systems Science, Graduate School of Eng., Utsunomiya

University (7-1-2 Yoto, Utsunomiya 321-8585, Japan) E-mail: akinorin@cc.utsunomiya-u.ac.jp
\end{abstract}

The objective of this study is to develop the numerical model, which can accurately predict the static behavior of the stud shear connectors those are often used in the hybrid structures. For this purpose, it is important to consider the proper model of the shear force transmission from the stud shank to the surrounding concrete. To achieve this requirement, one-dimensional bearing springs whose characteristics are determined by the bearing test of concrete are introduced. The numerical method and the model proposed in this paper are validated by comparing its predictions such as strain and slip with the experimental ones.

Key Words : bearing force, nonlinear finite element analysis, stud shear connector, strain behavior, slip, push- and pull-out test

\section{Introduction}

Stud shear connectors are often employed in the composite structures to allow composite action of the members made of different materials. To observe the complicated nature of the composite structure or its component, an experimental investigation is needed. In addition to the experimcntal investigation, numcrical cvaluation plays a significant role to examine mechanical properties of composite structures. To conduct experiment with varying geometric properties is a time consuming matter, whereas numerical analysis can easily check the effect of any variation. The advantage and necessity of the numerical evaluation are the followings. While the base of the stud shank is subjected to the most severe deformation, it is not easy to measure the strain at the base of studs experimentally, due to the welding at the base and necessity of the protection of the strain gauges. Moreover, the bearing characteristics between the stud shank and the surrounding concrete can be easily estimated through the nu- merical analysis rather than experiment.

For numerical investigation, proper modeling of the composite system such as the stud shear connector, the surrounding concrete of the stud shank and interaction between them play an important role and the accuracy of the analysis fully depends on it. Therefore, the shear force transmission from the stud shank to the surrounding concrete should be clarified. Moreover, the type of the beam element used in the numerical simulation also has much effect on the accuracy of the numerical evaluation.

In this context, Civjan and Singh ${ }^{1)}$ investigated the behavior of the studs in the modified composite push- and pull-out specimens under fully reversed cyclic loading experimentally and numerically. FE analysis with 20 -noded solid element of push- and pull-out specimens was performed. One-fourth of the specimen was modeled based on the geometric and loading symmetry. Nakajima et al. ${ }^{2)}$ investigated the behavior of stud shear connectors under the pulsating and alternating load conditions experimentally and nu- 


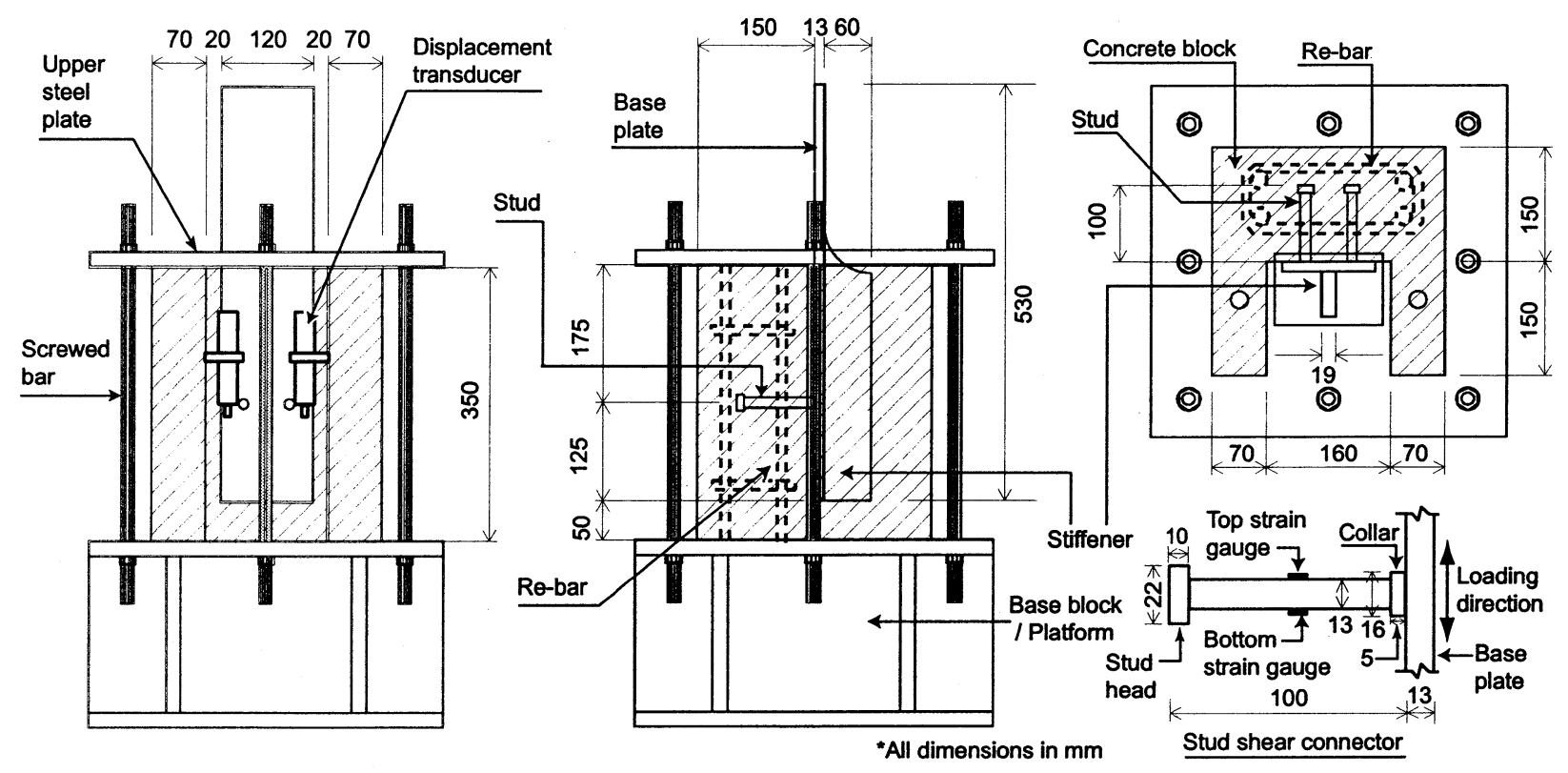

Fig. 1 Specimen details

merically. Two-dimensional nonlinear BernoulliEuler beam theory and one-dimensional spring with linear hardening were employed respectively for the studs and bearing force of concrete.

In the present study, the authors improve the accuracy of the strain and slip behavior of the stud shear connector based on the method proposed by Nakajima et al. ${ }^{2)}$. For this purpose, the surrounding concrete of the stud shank is considered as one-dimensional nonlinear bearing springs. The accuracy of the numerical evaluation mostly depends on the proper modeling of the bearing force. Consequently, an original constitutive model of the bearing springs have been developed based on the bearing test. Nonlinear finite element method along with Timoshenko beam theory is employed for the numerical analysis. The numerical results are compared with the experimental ones to validate the numerical analysis.

The entire research is comprised of three phases. Firstly, modeling of the stud and the base plate used in the push- and pull-out specimen ${ }^{3)}$ and modeling of the bearing characteristics of the springs on the basis of the bearing test are developed. Secondly, a series of numerical analysis is carried out with the proposed model for the pushand pull-out specimen under the pulsating and alternating load conditions. In this paper, the load condition with the only compressive shear force cycles or the only tensile shear force cycles

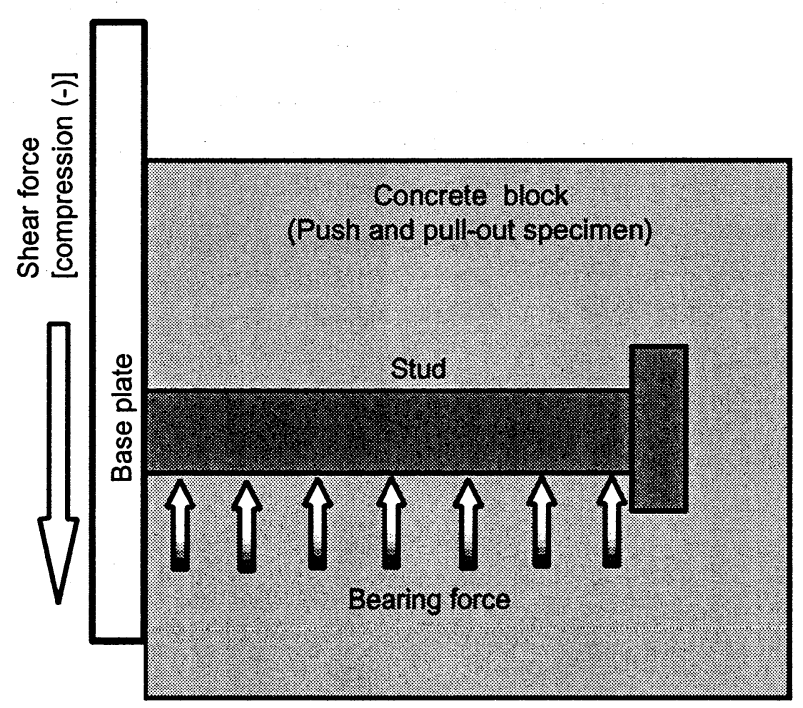

Fig. 2 Bearing force of concrete

is defined as the pulsating load condition and the reversed cyclic shear force is defined as the alternating load condition. Thirdly, numerical results are compared with the experimental ones to examine the feasibility of the method.

\section{Push- and Pull-out Specimen}

In this section the push- and pull-out specimen $^{3)}$ shown in Fig. 1, which is used later for the comparison, is briefly introduced. A pair of headed studs with diameter $13 \mathrm{~mm}$ and length $100 \mathrm{~mm}$ was welded on the base steel plate 


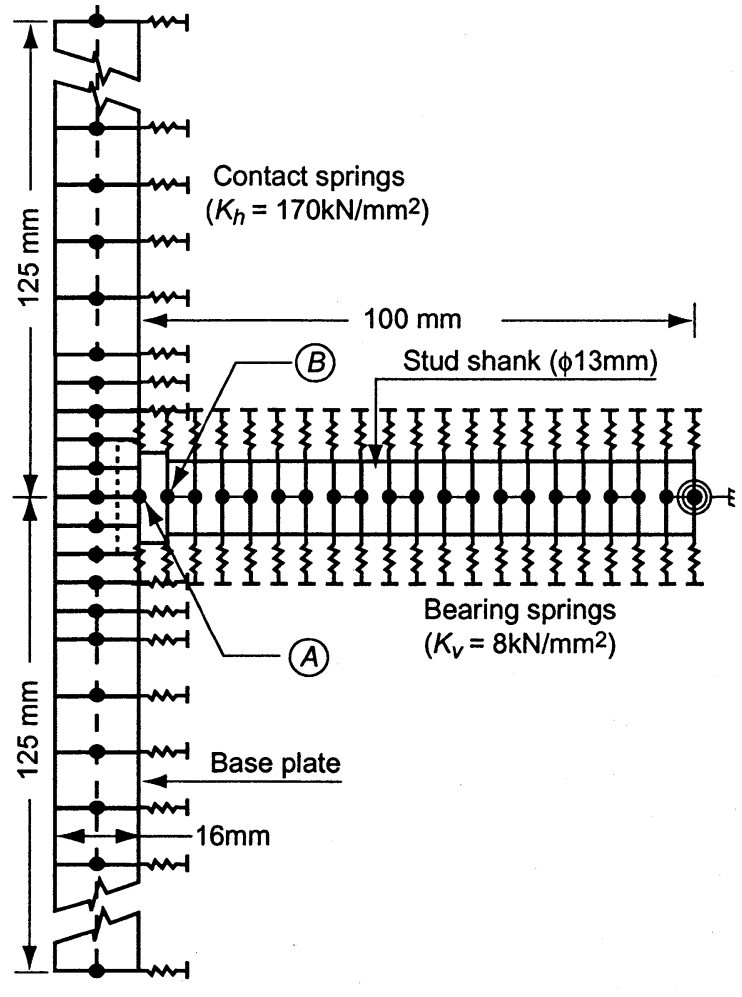

Fig. 3 Numerical model

$(530 \mathrm{~mm} \times 120 \mathrm{~mm} \times 13 \mathrm{~mm})$. The average size of the stud head and the collar are shown with the test specimen. To increase the stiffness of the base plate and to provide sufficient resistance against plate bending, another steel plate $(350 \mathrm{~mm} \times 60 \mathrm{~mm} \times 19 \mathrm{~mm})$ was welded to the base plate on the other side. The concrete block had a concave section shown in Fig. 1 so that the specimen should not rotate during the application of load to the top of the base plate. Two displacement transducers were installed to measure the slip between the concrete block and the base plate at the same level of the studs. One pair of strain gauges was installed at the mid height of each stud as shown in Fig. 1. The main objective of selecting the shape and size of the specimen was to realize easy application of pulsating and alternating loadings for the static and fatigue tests.

\section{Numerical Model and Analysis Method}

\subsection{Outline of Numerical Model}

The shear force applied to the composite system is transmitted through the bearing forces between the stud and the surrounding concrete in the transverse direction of stud shank as shown

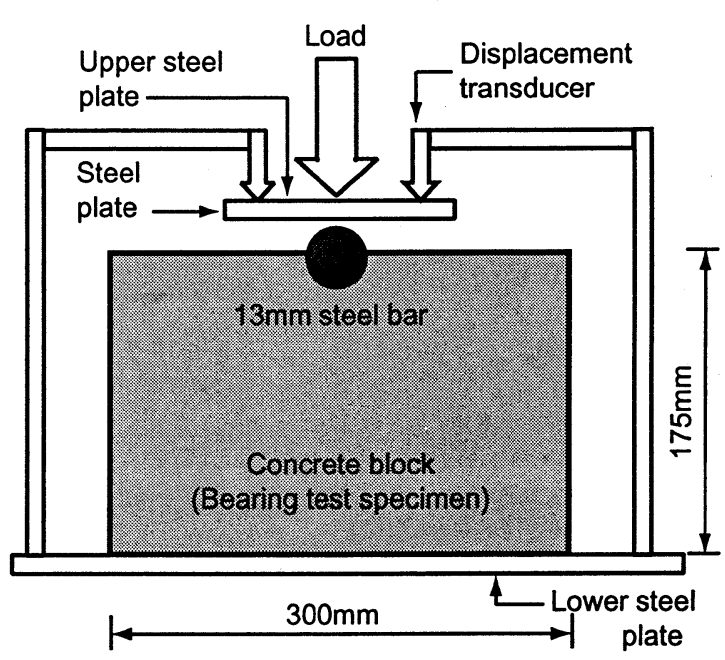

Fig. 4 Bearing test specimen

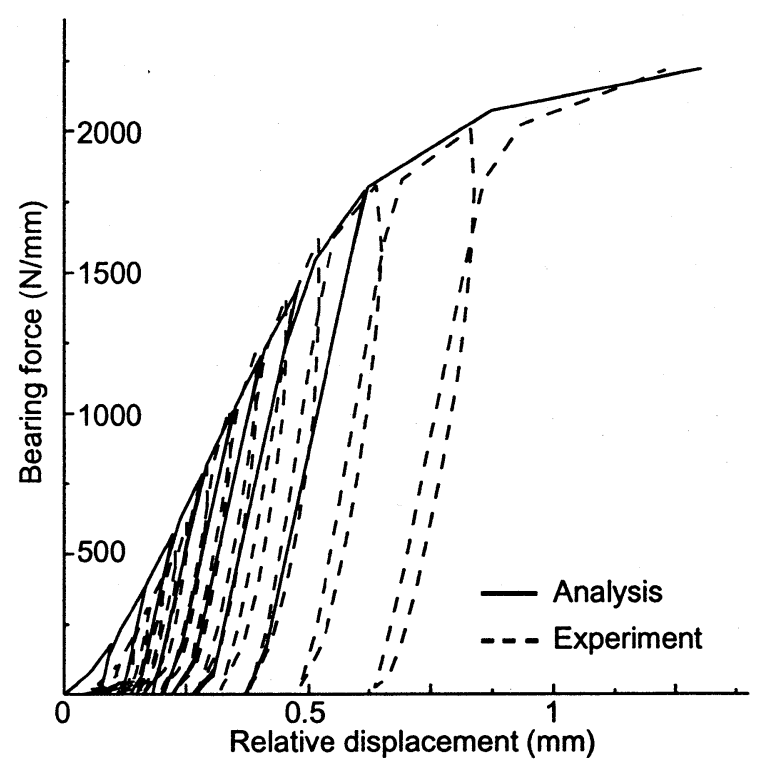

Fig. 5 Bearing force-relative displacement relation

in Fig. 2. The shear force considered in Fig. 2 is acting along downward direction means compression (negative shear force). In order to investigate the mechanical response of the stud shear connectors, it is important to develop appropriate model of the shear force transmission. In this connection, attention is paid to the modeling of the bearing force between the stud and concrete block for the purpose of the numerical analysis. Half of the specimen is modeled based on geometric and loading symmetry. Fig. 3 shows the numerical model of the stud shank with the base steel plate, bearing and contact springs employed for the numerical analysis. The stud of length $100 \mathrm{~mm}$ and diameter $13 \mathrm{~mm}$ is modeled as 20 beam-column elements and the base plate of 


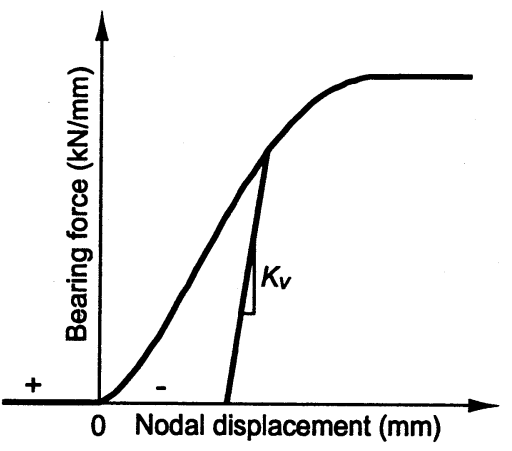

Fig. 6-a Bearing springs

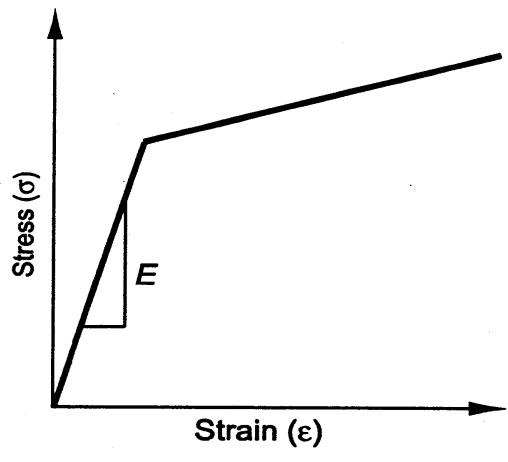

Fig. 6-b Stud and base plate

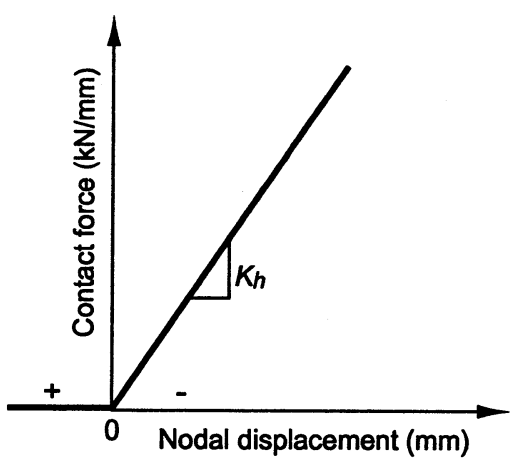

Fig. 6-c Contact springs

Fig. 6 Constitutive relations of different material

length $250 \mathrm{~mm}$, width $60 \mathrm{~mm}$ and thickness $16 \mathrm{~mm}$ is modeled as 26 beam-column elements. The thicker $(16 \mathrm{~mm})$ base plate is assumed rather than the actual one $(13 \mathrm{~mm})$ to include the effect of stiffener. Moreover, the stiffener was not welded directly behind the base of the stud shank. It was little far from the centerline of the stud section, and two fictitious elements with enough stiffness are provided between the centerline of the base plate and the base of the stud shank in order to fill the gap. The base plate is considered as the symmetrical one with respect to the axis of stud shank.

\subsection{Bearing Spring}

In the numerical analysis, it is very important to employ the proper bearing characteristics between the stud shank and the surrounding concrete. For this purpose, the bearing test as shown in Fig. 4 was conducted to observe the bearing characteristics. The bearing test specimen was composed of the concrete block with the same height from the fixed end to the centerline of the stud shank of the push- and pull-out specimen ${ }^{3)}$ shown in Fig. 1. The round steel bar with the same diameter and the length of the stud shank was employed in bearing test specimen. No reinforcing bar was arranged in the concrete block. The magnitude of the load applied to the upper steel plate placed on the steel bar and the relative displacement between the upper and lower steel plate were measured as shown in Fig. 4. The bearing force-relative displacement relation obtained from the bearing test is shown in Fig. 5. The ordinate shows the bearing force applied to the unit length of the steel bar in Fig. 4 and the abscissa shows the relative displacement. Ab- solute values are assumed for both the ordinate and abscissa.

Based on the experimental results the constitutive relation of the bearing springs is proposed. The fourth order polynomial curve

$$
P=a_{1} \delta+a_{2} \delta^{2}+a_{3} \delta^{3}+a_{4} \delta^{4}
$$

is assumed for nonlinear hardening to fit the envelope of the mechanical characteristics of the bearing springs shown in Fig. 6-a. Where, $P$ is the bearing force in $\mathrm{kN}$ per unit length and $\delta$ is the relative displacement in $\mathrm{mm}$ at any load level. The coefficients $a_{1}, a_{2}, a_{3}$ and $a_{4}$ are assumed as $1.1,9.4,-13.9$ and 5.5 respectively. The spring constant $\left(K_{v}\right)$ for unit length was estimated to be $8 \mathrm{kN} / \mathrm{mm}^{2}$ based on the unloading path of the bearing force-relative displacement relation as shown in Fig. 5. The bearing force for an element is distributed equally to two nodes, which belong to the element. So, the spring constant of the base and tip springs is assumed as a half of others. The bearing springs are assumed to be active only in compression and arranged between the stud shank and the virtual fixed end. One-dimensional return-mapping algorithm ${ }^{4}$ is employed to compute plastic effect of the bearing springs.

\subsection{Stud and Base Plate}

Two-dimensional nonlinear finite element technique in conjunction with Timoshenko beam theory is utilized for the stud and the base steel plate. The welding at the base of the stud shank in the push- and pull-out specimen modeled as an element of diameter $16 \mathrm{~mm}$ and length $5 \mathrm{~mm}$ on average. The stud and the base plate are modeled as the beam-column element with geometrical and material nonlinearities. For geometrical 


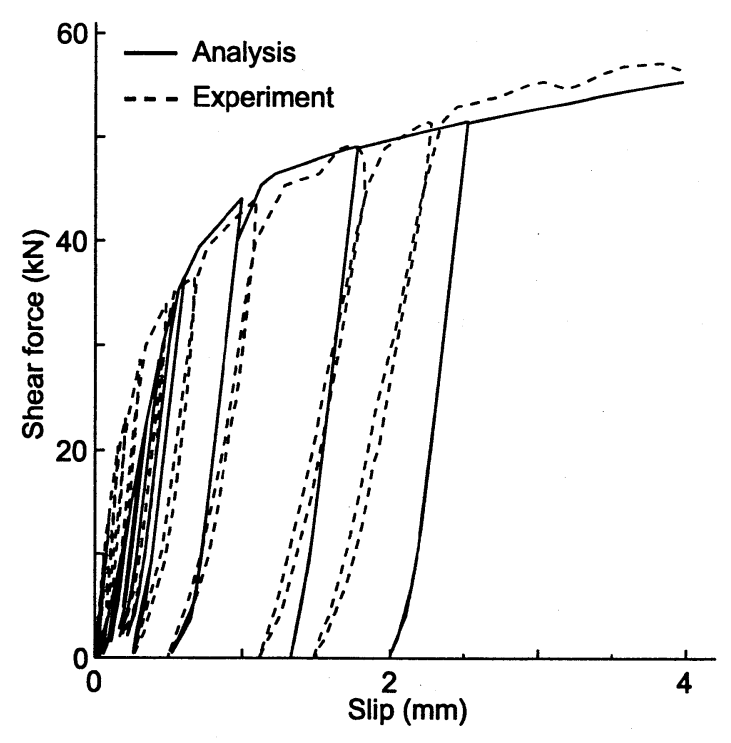

Fig. 7-a Pulsating load condition

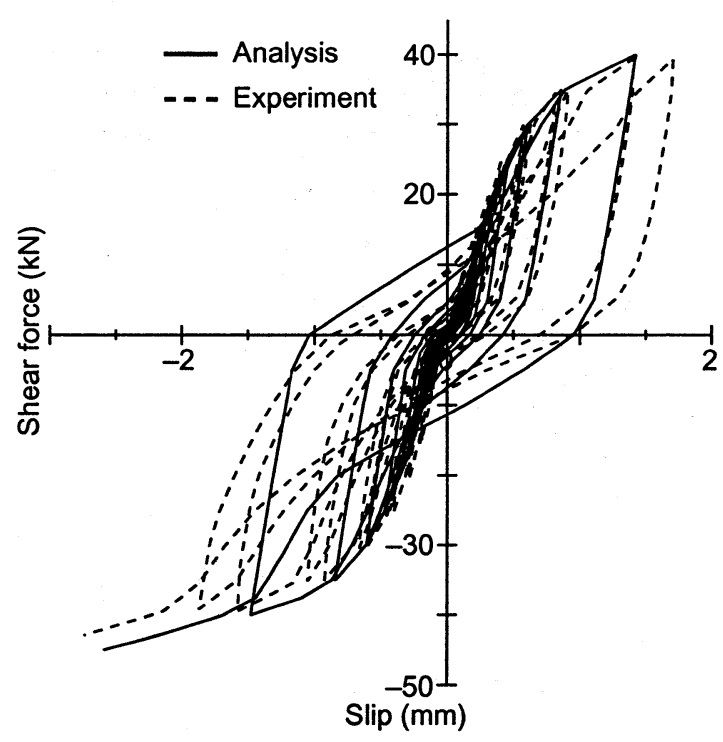

Fig. 7-b Alternating load condition

Fig. 7 Shear force-slip relations

nonlinearity, finite displacement and infinitesimal strain formulation are taken into account since it is rational and realistic for general framed structures. For the constitutive relation of the steel material shown in Fig. 6-b, von Mises yield criterion, associate flow rule and linear kinematic hardening are employed .

The kinematic hardening parameter $H$ is assumed as $1 \%$ of the Young's modulus $E$. The Young's modulus $E$ and the Poisson's ratio $\nu$ are respectively assumed as $210 \mathrm{kN} / \mathrm{mm}^{2}$ and 0.3 for the stud and the base plate. The initial yield stress $\sigma_{y}$ for the stud and the base plate is respectively assumed to be $360 \mathrm{~N} / \mathrm{mm}^{2}$ and $300 \mathrm{~N} / \mathrm{mm}^{2}$. The effective shear coefficient $(\kappa)$ is assumed as 0.89 and 0.85 for the stud and base plate sections. Two stress components that are one normal component in longitudinal direction and another shear component in cross section are considered and other components are assumed to zero. To simulate above plastic constitutive relation with two stress components, a particular stress integrating algorithm by modification of return-mapping algorithm ${ }^{4}$ ) is employed here.

\subsection{Contact Spring and Other}

The contact surface between the base plate and the concrete block is modeled as a type of penalty ${ }^{5}$ spring provided horizontally as shown in Fig. 3. The spring constant $\left(K_{h}\right)$ of the contact springs is determined by the trial and error method and its magnitude is sufficiently large as
$170 \mathrm{kN} / \mathrm{mm}^{2}$. The spring works only in compression as shown in Fig. 6-c. A rotational spring is incorporated into the stud head so as to take into account the rotational restriction at the stud head. The stud head is also restrained horizontally.

\section{Comparison of Numerical and Ex- perimental Results}

The numerical responses obtained from the nonlinear finite element analysis are discussed in this section and are compared with the experimental ones under the pulsating and alternating load conditions.

\subsection{Shear Force-Slip Relations}

Fig. 7 shows the relation between the shear force and the slip obtained from the numerical analysis. The shear force-slip under the pulsating and alternating load conditions are shown in Figs. 7-a and 7-b by solid line. The corresponding experimental relations from the push- and pull-out test ${ }^{3)}$ are also plotted in these figures by the dashed lines. The ordinate indicates the shear force applied per one stud and the abscissa indicates the slip between the concrete block and the base plate. Absolute values are assumed for both the shear force and slip in Fig. 7-a. In the numerical analysis, the slip is estimated by the vertical displacement at the base node of the stud shank named $\boldsymbol{A}$ in Fig. 3. 


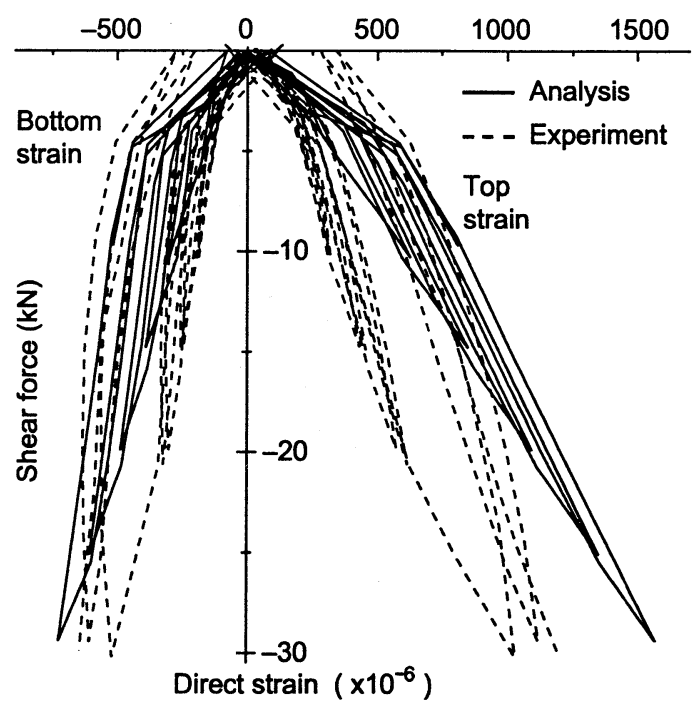

Fig. 8-a Pulsating load condition

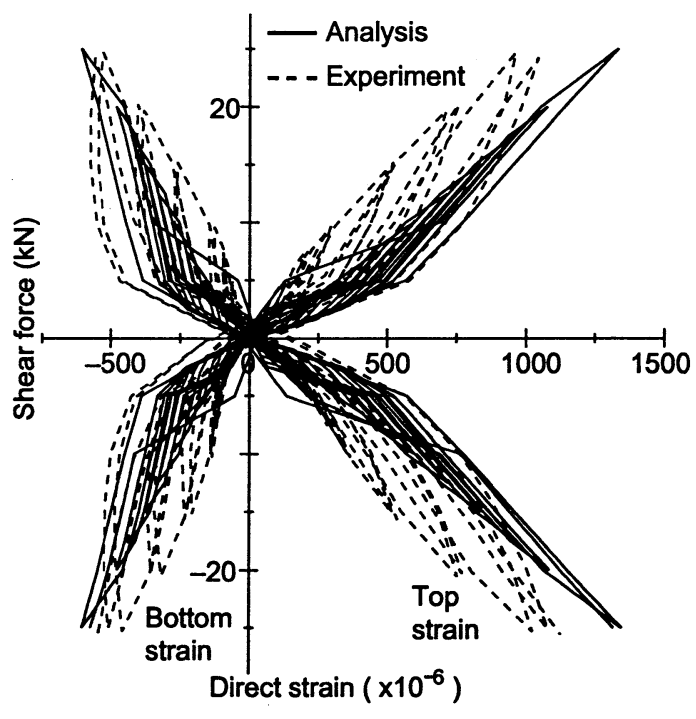

Fig. 8-b Alternating load condition

Fig. 8 Shear force-direct strain relations at mid height

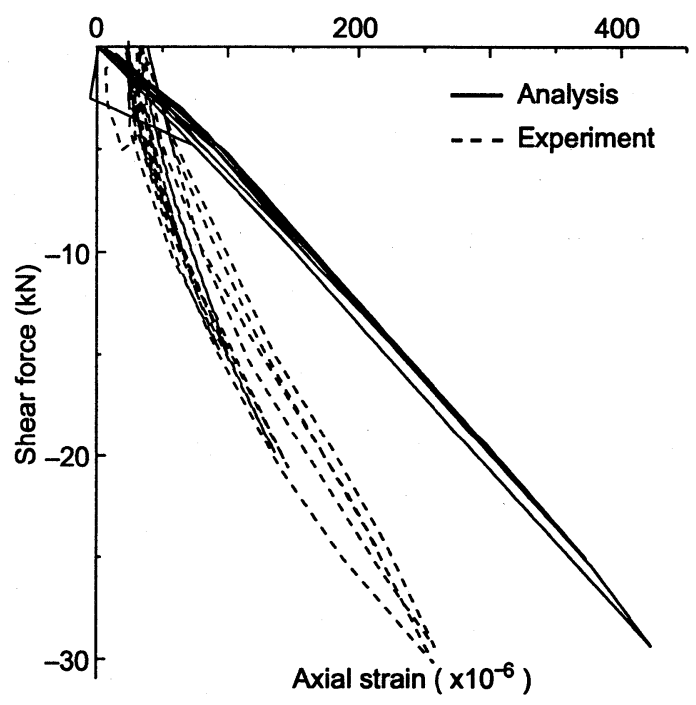

Fig. 9-a Pulsating load condition

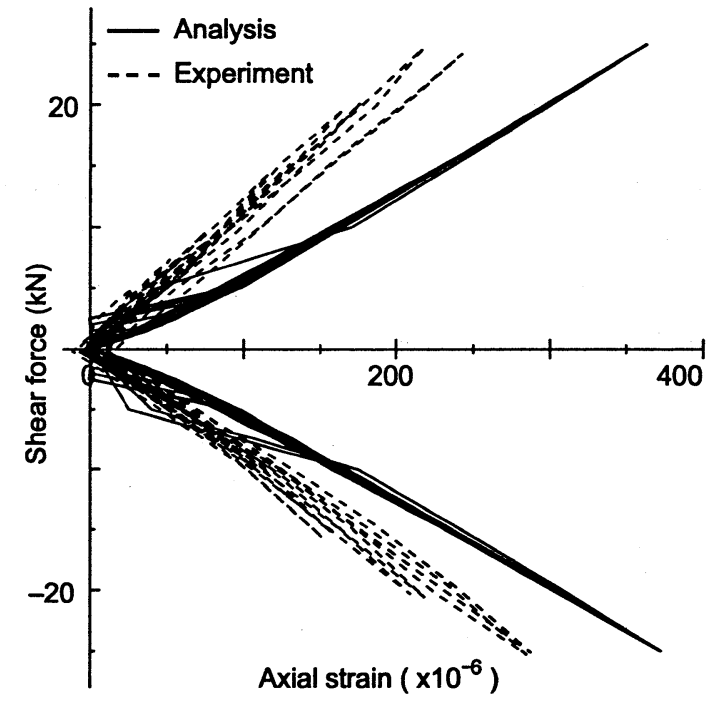

Fig. 9-b Alternating load condition

Fig. 9 Shear force-axial strain relations at mid height

It can be seen that the relations obtained from the analysis agree with those obtained from the experiment. According to Fig. 7-a, in case of the experiment the unloading pass and also loading pass until the peak shear force of the preceding loading cycle follow the same path in lower load range but follow different paths in higher load range. For the numerical analysis, the unloading and loading passes until the peak shear force of the preceding cycle follow the same path even in higher load range.

The slope of the unloading pass of the numerical result is composed by the combination of the Young's modulus $(E)$ of the stud material and the spring constant $\left(K_{v}\right)$ of the bearing springs.
Between these two parameters, spring constant has a significant influence on the unloading stiffness. Although, the slope of the unloading pass obtained from the experiment is about $80 \%$ of numerical one, the envelope curves shows better correlation between each other. In Fig. 7-b, the loading pass does not trace on the unloading pass, follows rather different path. This observation occurs because of the change in direction of the loading from compression to tension or vice versa. In this figure, the unloading slopes as well as the envelope curves of the numerical relation agree well with the experimental one. 


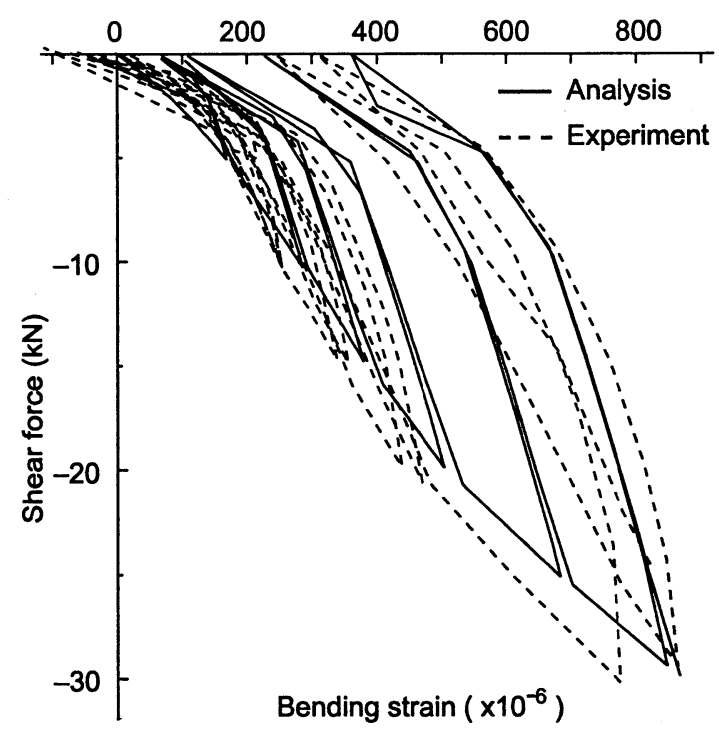

Fig. 10-a Pulsating load condition

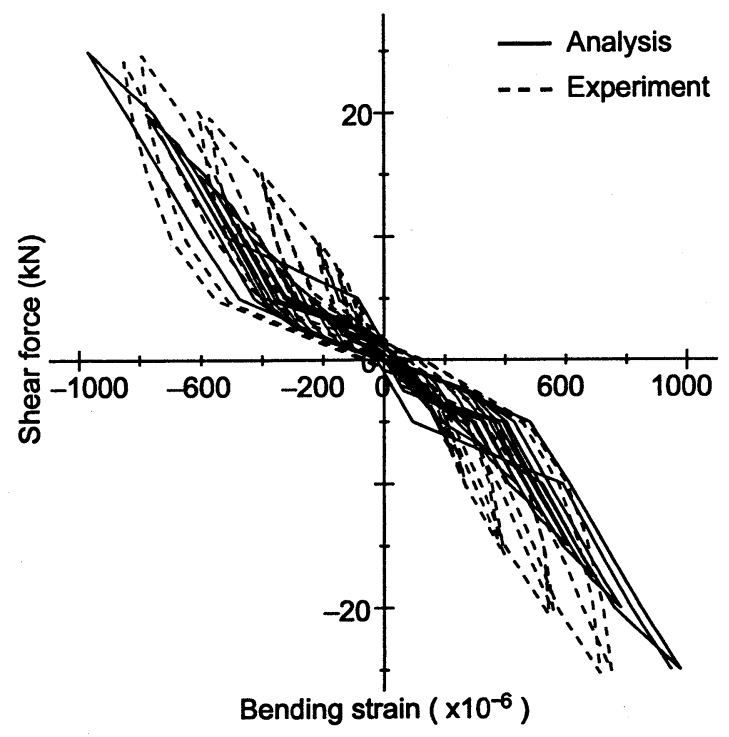

Fig. 10-b Alternating load condition

Fig. 10 Shear force-bending strain relations at mid height

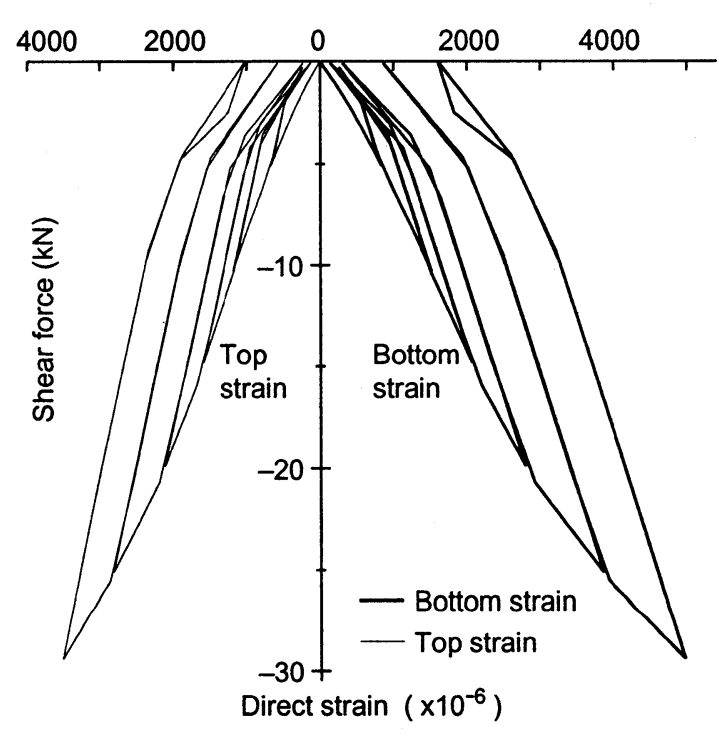

Fig. 11-a Pulsating load condition

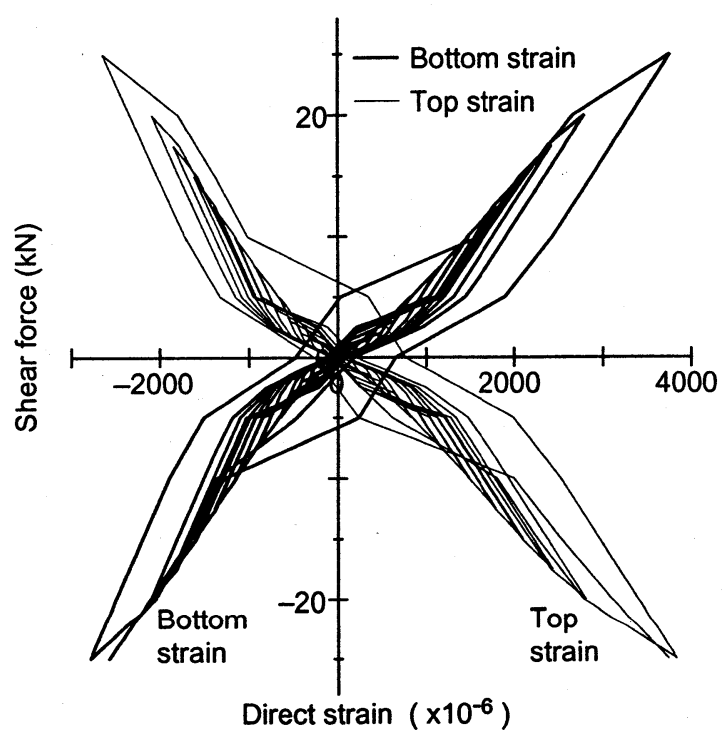

Fig. 11-b Alternating load condition

Fig. 11 Shear force-direct strain relations at base

\subsection{Bearing Force-Relative Displacement Relation}

The bearing force of concrete is modeled as one-dimensional bearing spring arranged surrounding the stud shank for the numerical simulation. Fig. 5 shows the relation between the bearing force and the relative displacement obtained from the numerical analysis with the experimental result obtained from the bearing test. In the numerical model, the relative displacement is estimated by the vertical displacement at the node named $\boldsymbol{B}$ as shown in Fig. 3. The accuracy of the numerical findings mostly depends on the accuracy of the modeling of the bearing char- acteristics. According to Fig. 5, it can be seen that the agreement between the numerical and the experimental results is almost well.

\subsection{Strain Behavior at Mid Height of Stud Shank}

The relations between the shear force applied per one stud and the resultant strain at the mid height of the stud shank are shown in Fig. 8 for the pulsating and alternating load conditions. The solid lines stand for the results of the numerical analysis and the dashed lines for the experimental ones. According to the figure, numerical results agree with the experimental ones quali- 
tatively for both the load conditions. It is not easy to simulate the complex behavior of the hybrid structure exactly. The numerical analysis presented here can predict the behavior of stud shear connector with a certain degree of accuracy. This means the agreement between the numerical and experimental results occur sometimes quantitatively and sometimes qualitatively. Fig. 8 includes both the top and bottom strain at the mid height of the stud shank, which were measured by the top and bottom strain gauges illustrated in Fig. 1. According to Fig. 8, it can be seen that the absolute value of strains at the top and bottom are different. Furthermore, the absolute value of the top strain is larger than the bottom one for the pulsating load condition and compression-sided loading of the alternating load condition. On the other hand, top strain is smaller than the bottom one for tension-sided loading of the alternating load condition. This is the reason why the stud shank is subjected to the axial force as well as the bending.

The axial strain and the bending strain are estimated based on the elementary beam theory for the pulsating and alternating load conditions and are shown in Figs. 9 and 10 respectively. Both the axial strain and bending strain relations obtained by the numerical analysis evaluate the ones obtained by the experiment qualitatively. However, in Figs. 8, 9 and 10, it can be seen that the numerical responses somewhat overestimate in respect of the experimental responses. The shear force-direct strain and shear force-bending strain relations in Figs. 8 and 10 correlate better than the shear force-axial strain relation in Fig. 9. The axial force in the stud shank is caused due to the deformation of the base steel plate as well as the restricted condition employed at the stud head. This behavior is generally observed in the actual composite girder, for instance the flange of the steel girder shows same behavior during the shear transmission of the stud. However, the axial strain relations obtained from numerical analysis shows similar tendency with the experimental ones.

Considering the mid height strain behavior, since the numerical results agree with the experimental results, it can be expected that the base strains from the numerical analysis agree with the experimental ones for both the pulsating and alternating load conditions. Fig. 11 shows the relations between the shear force and direct strain behavior under the pulsating and alternating load conditions. The strain behavior at the base in Figs. 11-a and 11-b are similar to the mid height ones in Figs. 8-a and 8-b. According to Figs. 8 and 11, the axial strain and the bending strain at the base are about 1.5 times and 3.5 times larger than the mid height ones. The curvature at the base section is opposite to that at the mid height section.

\section{Conclusions}

A numerical method for evaluating the strain responses and slip behavior of the stud shear connector has been developed in this paper. The present method includes one-dimensional bearing springs with nonlinear hardening and beamcolumn element with geometrical and material nonlinearities. Since the estimation by this method agrees with the results of the experiment quantitatively for the shear force-slip relations and bearing force-relative displacement and qualitatively for the shear force-strain relation, the feasibility of this method for predicting the behavior of the stud shear connector has been proved. The base strain responses, which cannot be observed easily by the experiment, can be evaluated easily by the numerical analysis presented here.

\section{REFERENCES}

1) Civjan, S.A. and Singh, P.: Behavior of shear studs subjected to fully reversed cyclic loading, Journal of Structural Engineering, ASCE, Vol.129, No.11, pp.1466-1474, 2003.

2) Nakajima, A., Saiki, I., Kokai, M., Doi, K., Takabayashi, Y. and Ooe, H.: Cyclic shear force-slip behavior of studs under alternating and pulsating load condition, Engineering Structures, Elsevier Science Ltd., Vol.25, pp.537-545, 2003.

3) Nakajima, A., Kinoshita, K., Saiki, I., Miah, Md.K., Ooe, H. and Sakai, Y.: Static and fatigue strength of stud under alternating load conditions, Steel Construction Engineering, JSSC, Vol.10, No.37, pp.31-41, 2003 [in Japanese].

4) Simo, J.C. and Hughes, T.J.R.: Computational Inelasticity, Springer, 1998.

5) Wriggers, P.: Computational Contact Mechanics, Wiley, 2002.

(Received April 16, 2004) 